\title{
Palladium(II) carboxylates and palladium(I) carbonyl carboxylate complexes as catalysts for olefin cyclopropanation with ethyl diazoacetate
}

\author{
Oleg N. Shishilov, ${ }^{* a}$ Tatiana A. Stromnova, $\dagger^{a}{ }^{\text {Juan Cámpora, }}{ }^{* b}$ Pilar Palma, ${ }^{b}$ M. Ángeles Cartes ${ }^{b}$ and \\ Luís Miguel Martínez-Prieto ${ }^{b}$
}

\author{
Received 10th March 2009, Accepted 14th May 2009 \\ First published as an Advance Article on the web 8th July 2009 \\ DOI: 10.1039/b904891j
}

\begin{abstract}
Palladium(I) carbonyl carboxylate complexes $\left[\mathrm{Pd}(\mu-\mathrm{CO})\left(\mu-\mathrm{RCO}_{2}\right)\right]_{n}\left(\mathrm{R}=\mathrm{Me}, n=4 ; \mathrm{R}=\mathrm{CMe}_{3}, n=6\right)$ and the corresponding palladium(II) carboxylates (acetate and pivalate) catalyze the cyclopropanation of olefins with ethyl diazoacetate. The performance of these catalysts is similar in terms of selectivity and cyclopropane yields, regardless of the oxidation state of the metal center. However the rates of the cyclopropanation reactions are significantly higher for the acetate based catalysts than for the pivalate derivatives, which suggests that the main catalytic species are carboxylate containing palladium complexes. Kinetic measurements show that reaction rates are independent of the olefin concentration when these are 1-hexene or styrene, but norbornene exerts an inhibitory effect. In spite of this, competition experiments indicate that the cyclopropanation of styrene is 2.2 times as favorable as that of 1-hexene for any of the four catalysts. These observations indicate that while the rate-determining formation of the intermediate palladium carbenoid species is controlled by the catalyst structure, this is followed by a rapid and less specific cyclopropanation step that is not affected by the nature of the carboxylate groups present in the catalyst. An independent test using a 1:1 benzene/cyclohexane mixture of solvents showed that the transfer of ethoxycarbonylcarbene $\left(: \mathrm{C}\left(\mathrm{CO}_{2} \mathrm{Et}\right) \mathrm{H}\right)$ to these molecules is unselective (relative rate of benzene/cyclohexane functionalization $\approx 1.8$, independent of the catalyst). This result can be interpreted as an indication of the involvement of free ethoxycarbonylcarbene in the carbene transfer step.
\end{abstract}

\section{Introduction}

Cyclopropanes are part of many natural and biologically active compounds ${ }^{1}$ and versatile synthons for the construction of a wide variety of organic molecules. ${ }^{2}$ Catalytic olefin cyclopropanation with diazo compounds stands out among the available cyclopropane synthesis methods because of its versatility. ${ }^{3}$ Many metal compounds, especially of rhodium, ${ }^{4}$ copper, ${ }^{5}$ cobalt, ${ }^{6}$ ruthenium ${ }^{7}$ and palladium ${ }^{8}$ catalyze this reaction. Some of these catalysts are relatively simple compounds, such as metal halides or carboxylates. For example rhodium(II) and palladium(II) carboxylates are well known cyclopropanation agents. However, while a number of rhodium(II) carboxylates including chiral derivatives, ${ }^{9}$ have been tested, only palladium(II) acetate has been applied for this purpose. The latter compound has found wide use in olefin cyclopropanation with diazomethane, ${ }^{10}$ and to a lesser extension with alkyl diazoacetates. ${ }^{11}$

The mechanism of olefin cyclopropanation by palladium complexes has been addressed by theoretical means, but the problem is still a subject of discussion. There is a general agreement in that the active species are either palladium carbene or carbene-

anstitute of General and Inorganic Chemistry, Russian Academy of Science (RAS), Leninsky prospekt, 31, Moscow, 119991, Russia. E-mail: oshishilov@gmail.com; Fax: +7 495 9541279; Tel: +7 4959554805

${ }^{b}$ Instituto de Investigaciones Químicas, CSIC-Universidad de Sevilla, c/Américo Vespucio, 49, 41092, Sevilla, Spain. E-mail: campora@iiq. csic.es; Fax: +34 954460565; Tel: +34 954489555

$\dagger$ Deceased. like (carbenoid) complexes, but not in the oxidation state and the structure of such intermediates. Thus, in a computational study, Bernardi et al. propose that diazomethane reacts with $\mathrm{PdCl}_{2}\left(\mathrm{PR}_{3}\right)$ to afford $\mathrm{Pd}(\mathrm{II})$ carbenoid complexes arising from $\mathrm{CH}_{2}$ insertion into the $\mathrm{Pd}-\mathrm{Cl}$ or $\mathrm{Pd}-\mathrm{P}$ bonds, which subsequently perform olefin cyclopropanation via a multistep process involving palladacyclobutane intermediates. ${ }^{12}$ Branchadell et al. devoted another theoretical study to the reaction catalyzed by palladium carboxylates (modeled as palladium formate), concluding that also in this case the most favorable process is methylene insertion into the $\mathrm{Pd}-\mathrm{O}$ bonds, but the resulting methyleneformate $\left(\mathrm{PdCH}_{2} \mathrm{OC}(\mathrm{H})=\mathrm{O}\right)$ complexes are not active catalysts. The cyclopropanation step would be performed by a true $\mathrm{Pd}(\mathrm{II})$ methylene complex generated by reaction of the methyleneformate species with additional diazomethane. ${ }^{13}$ According to Straub, palladium acetate would be reduced to $\mathrm{Pd}(0)$ olefin complexes, and the subsequent reaction steps would be generation of a $\operatorname{Pd}(0)$ methylene complex, followed by palladacyclobutane formation and reductive coupling. ${ }^{14}$ In spite of the diversity of the proposed intermediates, it is usually assumed that the palladium-catalyzed reaction is carried out by relatively simple, mononuclear species.

Non-heteroatom stabilized $\mathrm{Pd}(\mathrm{II})$ alkylidene complexes are highly reactive, and generally unstable species, but a few examples of compounds of this type have been isolated and characterized. ${ }^{15}$ It has also been shown that a stable $\mathrm{Pd}(\mathrm{I})$ cluster palladium carbene complex, $\left[\mathrm{Pd}\left(\mu-\mathrm{MeCO}_{2}\right)\left(\mu-\mathrm{CPh}_{2}\right)\right]_{4}$, containing only bridging diphenylcarbene and acetate ligands, is formed when the carbonylacetate cluster complex $\left[\mathrm{Pd}\left(\mu-\mathrm{MeCO}_{2}\right)(\mu-\mathrm{CO})\right]_{4}$ is 
reacted with diphenyldiazomethane (Scheme 1) ${ }^{16}$ This reaction involves the formal displacement of the carbonyl ligands by the diphenylcarbene fragment.

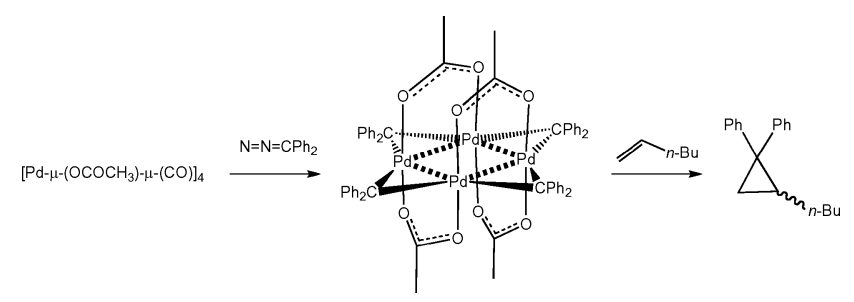

Scheme 1

In contrast with $\mathrm{Pd}(\mathrm{II})$ mononuclear alkylidene species, whose capability to transfer their carbene ligand to olefins has not been demonstrated experimentally, the tetranuclear palladium diphenylcarbene cluster does react stoichiometrically with 1-hexene to afford the corresponding cyclopropanation product, 1,1-diphenyl-2-butylcyclopropane. This result, coupled to the recent detection of catalytically active nanoparticles in the cyclopropanation of cyclohexanone catalyzed by palladium acetate ${ }^{17}$ suggest that a number of polynuclear palladium species ranging from clusters to nanosized particles could be active catalysts in olefin cyclopropanation reactions. In order to check this hypothesis, we decided to investigate the performance of cluster-type palladium complexes as cyclopropanation catalysts, and compare them with the corresponding carboxylates. Since the tetranuclear carbene $\left[\mathrm{Pd}\left(\mu-\mathrm{MeCO}_{2}\right)\left(\mu-\mathrm{CPh}_{2}\right)\right]_{4}$ is difficult to prepare and it is isolated only in low yields, palladium(I) carbonylcarboxylates appear as more suitable catalyst precursors. The latter form a family of structurally related compounds displaying planar, cyclic $\mathrm{Pd}_{2 n}$ structures where palladium atoms are alternatively bridged by carboxylate and carbonyl ligands. ${ }^{18}$ In this paper, we describe the cyclopropanation of three olefins (1-hexene, styrene and norbonene) by two carboxylates (acetate, $\operatorname{Pd}(\mathrm{Ac})_{2}$; pivalate, $\left.\mathrm{Pd}(\mathrm{Piv})_{2}\right)$ and the corresponding carbonyl carboxylate derivatives $(\mathrm{Pd}(\mathrm{CO})(\mathrm{Ac})$ and $\mathrm{Pd}(\mathrm{CO})(\mathrm{Piv}))$. The structures of these compounds are shown in Chart 1. While the two carboxylates have triangular $\mathrm{Pd}_{3}$ cores, the carbonyl acetate $\mathrm{Pd}(\mathrm{CO})(\mathrm{Ac})$ and carbonyl pivalate $\mathrm{Pd}(\mathrm{CO})(\mathrm{Piv})$ contain square $\left(\mathrm{Pd}_{4}\right)$ and hexagonal $\left(\mathrm{Pd}_{6}\right)$ cores, respectively.
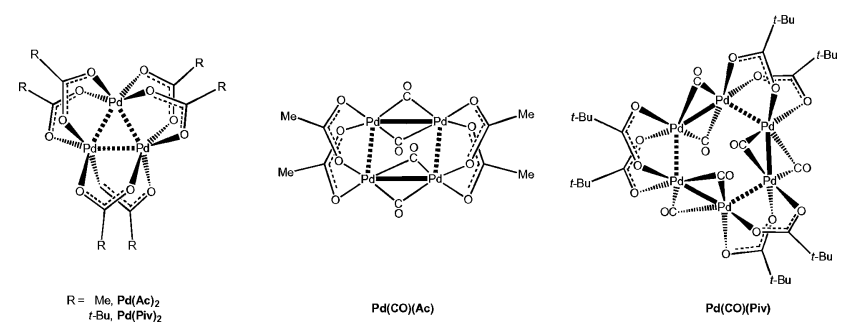

Chart 1

\section{Results and discussion}

As already mentioned, palladium acetate is a well-known catalyst for olefin cyclopropanation. Noels $e t$ al. have described the cyclopropanation of a wide number of olefins by alkyl diazoesters with this catalyst. ${ }^{11 b}$ In our study, we focused on three olefins, 1-hexene (HX), styrene (ST) and norbornene (NB), using ethyl diazoacetate (EDA) as cyclopropanating agent. Under similar conditions to those employed by Noels et al., complexes Pd(Piv) ${ }_{2}$, $\mathrm{Pd}(\mathrm{CO})(\mathrm{Ac})$ and $\mathrm{Pd}(\mathrm{CO})(\mathrm{Piv})$ proved active cyclopropanation catalysts as well. Three sets of cyclopropanation experiments were carried out. In two of them, the catalyst was added to a toluene solution containing EDA and olefin in molar ratios 1:5 and 1:10, respectively, and the reactions were allowed to proceed until EDA was fully consumed. In the third set, EDA was slowly added over $3 \mathrm{~h}$ to the reaction mixture containing EDA and olefin in 1:5 ratio, using a syringe pump. GC and GC-MS analyses of the reaction mixtures show that cyclopropanes (as cis-trans mixtures) are formed as the main products of these reactions $(50-90 \%)$, together with minor amounts of diethyl maleate (DEM) and fumarate (DEF) $(<10 \%$ combined yield). In addition, gas chromatograms of the reaction mixture systematically display three minor peaks in 1:4:5 relative intensity ratio, whose MS spectra are consistent with products arising from addition of ethoxycarbonylcarbene $\left(\left(\mathrm{EtO}_{2} \mathrm{C}\right) \mathrm{HC}:\right)$ to the solvent. Other authors have detected the formation of these three products, which have been identified as isomeric cycloheptatrienes resulting from carbene insertion into the toluene ring $(\mathrm{CI})$, as shown in Scheme 2. ${ }^{11 \mathrm{~b}, 19}$

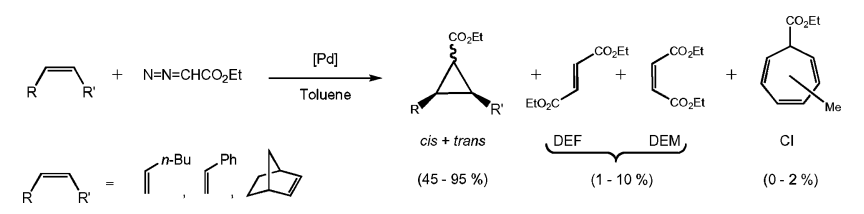

Scheme 2

The products arising from 1-hexene $\mathrm{e}^{4 \mathrm{~b}}$ and styren $\mathrm{e}^{20}$ were identified as cis (minor) and trans (major) cyclopropanes by comparison of the corresponding ${ }^{1} \mathrm{H}$ NMR spectra with those reported in the literature. In the case of norbonene, two cyclopropanes are formed as well, but the available literature data did not allow stereochemical assignment. ${ }^{21} \mathrm{We}$ assigned the signals of the ${ }^{1} \mathrm{H}$ and ${ }^{13} \mathrm{C}$ NMR spectra of the two observed cyclopropanation products on the basis of ${ }^{1} \mathrm{H}$-coupled (gated) ${ }^{13} \mathrm{C}$ spectrum and bidimensional ${ }^{1} \mathrm{H}-{ }^{13} \mathrm{C}$ heterocorrelations. In order to establish their configuration of the products, we calculated the chemical shifts of the four possible products (cis, exo; trans, exo; cis, endo and trans, endo) at the HF $6-311+\mathrm{G}(2 d, p)$ level, and compared them with those experimentally observed. As can be seen in Table 1, there is a reasonably good correlation between calculated and experimental chemical shifts, but only two signals are useful for assignation purposes. In the calculated spectra, the signals of methylene 3 are distinctly deshielded in the exo (ca. $50 \mathrm{ppm}$ ) as compared with the endo isomers ( $c a .27 \mathrm{ppm})$. The corresponding signals are experimentally found at $\delta 29,0$ and $28,9 \mathrm{ppm}$, both of them very close to the positions predicted for exo isomers. On the other hand, the calculation shows that carbon 5 is sensitive to the configuration of the cyclopropane ring. For the exo isomers, the calculated ${ }^{13} \mathrm{C}$ signals are significantly more upfield shifted for the trans $(13,9 \mathrm{ppm})$ than for the cis (20,4 ppm) isomer. Thus, the experimental observation of two methyne signals at $\delta 16,6$ and 21,5 for the minor and major isomers, respectively, suggesting that these correspond to the exo-trans and exo-cis isomers, respectively. This conclusion is reasonable, since assigns the least hindered configuration to the major isomer, as it is usually observed in cyclopropanation. 
Table 1 Comparison of calculated (HF 6-311+G $(2 d, p)$ ) ${ }^{13} \mathrm{C}$ NMR chemical shifts (ppm) for the four possible norbornene cyclopropanation products, and experimentally observed data

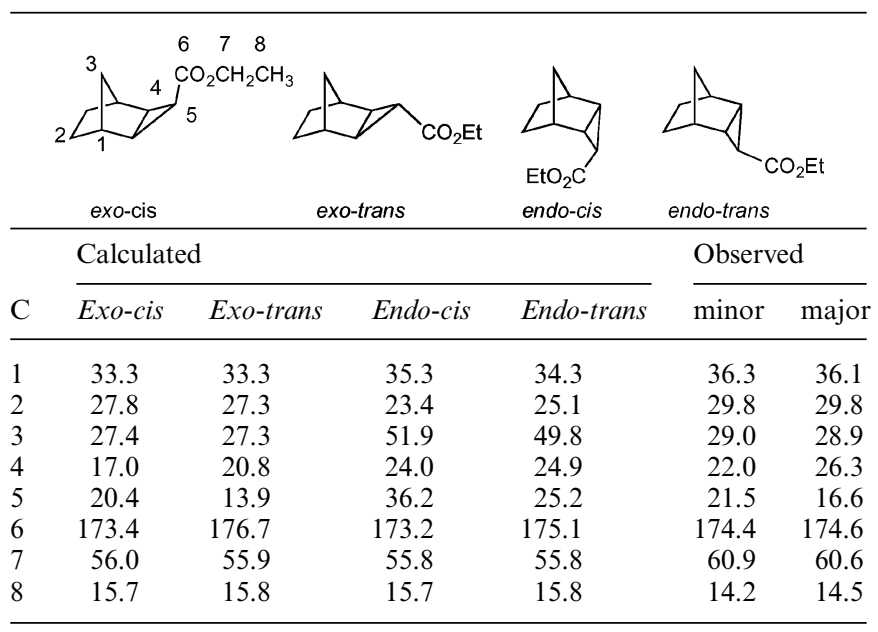

The ${ }^{1} \mathrm{H}$ NMR spectrum of the norbornene cyclopropanation mixture is complex, as most signals cluster between $1.0-1.6 \mathrm{ppm}$, but the bridge had proton $\mathrm{H} 1$ of the exo-trans and the exo-cis isomers give rise to well separated resonances in a clean spectral region at $\delta 2.30$ and $2.45 \mathrm{ppm}$, respectively, that are useful for diagnostic and integration purposes.

Gas chromatograms of the cyclopropanation products of styrene and norbornene display well resolved peaks for DEM, DEF, CI, and the cis and trans cyclopropanes, in successive elution order. In the case of 1-hexene, GC-MS spectrometry shows that $\mathrm{DEF}$ and the minor cyclopropane isomer are not resolved and elute in a single peak, the second one. In spite of this, the cis/trans cyclopropane ratio can be reasonably estimated by GC because the NMR spectra of selected examples confirms that amount of fumarate is small in comparison with that of the cis cyclopropane. The approximate amount of DEF can be estimated by assuming that, for each catalyst, DEF/DEM and CI/(DEF + DEM) ratios are approximately the same for the three olefins.

Table 2 collects data for the olefin cyclopropanation reactions, including yields (based on EDA), selectivity and reaction rates.
Although EDA is fully consumed in the course of the reactions, the combined yields of cyclopropane, DEF, DEM, and CI are generally not quantitative and seldom exceed $80 \%$. NMR spectra of the reaction mixtures are usually very clean, especially after evaporation of the volatile components, but they often show a broad hump under the ethyl $\mathrm{CH}_{2}$ resonances of the products, probably due to some polymeric or oligomeric material, which escapes detection by GC. Thus, the selectivity of the cyclopropanation reaction has been calculated as the percent fraction that the cis + trans cyclopropanes represents in the combined yields of the observed products of the reaction (cyclopropane, DEF, DEM and CI). Since side products DEM, DEF and CI are formed in small amounts, selectivities are generally high. In general, there are no important differences in the performances of the four catalysts, neither in terms of reaction yields or selectivity. Thus, cyclopropane trans / cis stereoselectivity ratios show small $(<15 \%)$ and essentially random deviations from their mean values that are 1.5, 2.1 and 1.3, for $\mathrm{HX}$, ST and $\mathrm{NB}$, respectively, with independency of the catalyst used. These trans/cis ratios are consistent with those previously reported for palladium acetate catalyzed reactions. ${ }^{11} \mathrm{DEF} / \mathrm{DEM}$ ratios are usually between 2 and 3 when EDA is added at once at the beginning of the reaction, but they tend to have higher values (up to 7) in slow addition experiments.

Fig. 1 summarizes the cyclopropanation yields and selectivities contained in Table 2.

In average, it can be appreciated that the yields tend to be slightly better with $\mathrm{Pd}(\mathrm{Piv})_{2}$, and somewhat worse with $\mathrm{Pd}(\mathrm{CO}) \mathrm{Piv}$ than the other two catalysts, but these depend on the specific reaction conditions. At the lowest olefin concentration (five-fold excess based on EDA), both cyclopropanation yields and selectivities increase in the order $\mathrm{HX}<\mathrm{ST}<\mathrm{NB}$. As pointed out by Noels et al., ${ }^{11 \mathrm{~b}}$ this sequence is consistent with the capability of these olefins to coordinate to the Pd center, and thus it reflects their relative reactivity towards the catalyst. However, while doubling the olefin concentration noticeably increases the HX cyclopropanation yields, this effect is less clearly observed for ST and not at all for NB. Hence, at sufficiently high olefin concentrations, cyclopropane yields tend to become leveled. In
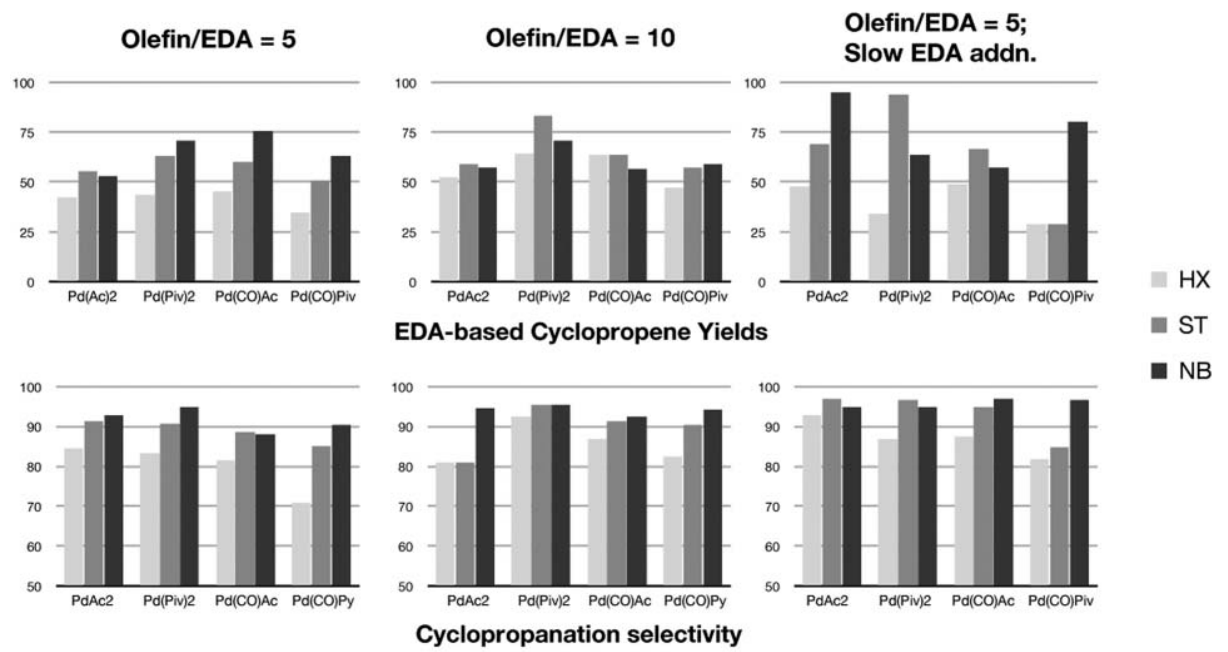

Fig. 1 Cyclopropanation yields (top) and selectivities (bottom). 
Table 2 Data for olefin cyclopropanation and EDA decomposition reactions

\begin{tabular}{|c|c|c|c|c|c|c|c|c|c|c|c|c|c|}
\hline \multirow[b]{2}{*}{ Entry } & \multicolumn{4}{|c|}{ Reaction conditions $^{a}$} & \multicolumn{3}{|l|}{ Yields $^{b}$} & \multicolumn{3}{|l|}{ Selectivity } & \multicolumn{3}{|c|}{ Reaction rates } \\
\hline & Catalyst & Procedure $^{c}$ & Olef. $^{d}$ & $\frac{\text { Olef }}{\text { EDA }}$ & $\begin{array}{l}\text { DEF + DEM } \\
\text { Yield }(\%)\end{array}$ & $\begin{array}{l}\text { Cyclopr. } \\
\text { yield (\%) }\end{array}$ & $\begin{array}{l}\text { CI yield } \\
(\%)\end{array}$ & $\begin{array}{l}\text { Cyclopr. } \\
\text { Select }(\%)^{e}\end{array}$ & $\begin{array}{l}\text { Cyclopr. } \\
\text { trans/cis }\end{array}$ & $\frac{\mathrm{DEF}}{\mathrm{DEM}}$ & $\begin{array}{l}t_{50} / \mathrm{min} \\
(\mathrm{EDA})^{f}\end{array}$ & 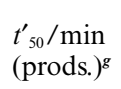 & $\begin{array}{l}\text { Cyclopr. TOF/ } \\
\mathrm{h}^{-1}\left(50^{\circ} \%\right)\end{array}$ \\
\hline 1 & $\mathrm{Pd}(\mathrm{Ac})_{2}$ & Initial & - & 0 & 13.5 & - & 2.36 & - & - & 1.8 & 6 & 12 & - \\
\hline 2 & $\operatorname{Pd}(\mathrm{Ac})_{2}$ & Initial & HX & 5 & 6.55 & 42.36 & 1.19 & 84.5 & 1.6 & 3.5 & 7 & 5 & 424 \\
\hline 3 & $\operatorname{Pd}(\mathrm{Ac})_{2}$ & Initial & HX & 10 & 10.83 & 52.70 & 1.52 & 81.0 & 1.7 & 4.3 & 5 & 7 & 527 \\
\hline 4 & $\mathrm{Pd}(\mathrm{Ac})_{2}$ & Slow addn & HX & 5 & 2.72 & 47.73 & 0.99 & 92.8 & 1.6 & h & - & - & - \\
\hline 5 & $\operatorname{Pd}(\mathrm{Ac})_{2}$ & Initial & ST & 5 & 4.25 & 55.57 & 0.92 & 91.5 & 2.1 & 3.3 & 7 & 9 & 417 \\
\hline 6 & $\operatorname{Pd}(\mathrm{Ac})_{2}$ & Initial & ST & 10 & 2.42 & 59.14 & 0.44 & 95.4 & 2.2 & 5.5 & 7 & 8 & 573 \\
\hline 7 & $\mathrm{Pd}(\mathrm{Ac})_{2}$ & Slow addn & ST & 5 & 1.14 & 68.97 & 1 & 97.0 & 2.1 & 3.8 & - & - & - \\
\hline 8 & $\operatorname{Pd}(\mathrm{Ac})_{2}$ & Initial & NB & 5 & 3.69 & 53.46 & 0.45 & 92.8 & 1.2 & 5.5 & 27 & 29 & 115 \\
\hline 9 & $\operatorname{Pd}(\mathrm{Ac})_{2}$ & Initial & NB & 10 & 2.88 & 57.21 & 0.3 & 94.7 & 1.2 & 5.4 & 30 & 35 & 116 \\
\hline 10 & $\operatorname{Pd}(\mathrm{Ac})_{2}$ & Slow addn & NB & 5 & 3.97 & 95.00 & 1.01 & 95.0 & 1.4 & 7.5 & - & - & - \\
\hline 11 & $\mathrm{Pd}(\mathrm{Piv})_{2}$ & Initial & - & 0 & 14.14 & - & 2.27 & - & - & 1.6 & $211^{i}$ & $171^{i}$ & - \\
\hline 12 & $\mathrm{Pd}(\mathrm{Piv})_{2}$ & Initial & HX & 5 & 7.66 & 43.92 & 1 & 83.5 & 1.5 & 3.3 & $30^{i}$ & $30^{i}$ & 69 \\
\hline 13 & $\mathrm{Pd}(\mathrm{Piv})_{2}$ & Initial & HX & 10 & 4.72 & 64.26 & 0.47 & 92.5 & 1.4 & 2.5 & $57^{i}$ & $50^{i}$ & 71 \\
\hline 14 & $\mathrm{Pd}(\mathrm{Piv})_{2}$ & Slow addn & HX & 5 & 4.35 & 34.39 & 0.77 & 87.1 & 1.7 & 5.8 & - & - & - \\
\hline 15 & $\mathrm{Pd}(\mathrm{Piv})_{2}$ & Initial & $\mathrm{ST}$ & 5 & 5.24 & 63.56 & 1.09 & 90.9 & 2.2 & 2.5 & $42^{i}$ & $36^{i}$ & 68 \\
\hline 16 & $\mathrm{Pd}(\mathrm{Piv})_{2}$ & Initial & ST & 10 & 3.42 & 83.16 & 0.35 & 95.7 & 2.2 & 2.9 & $55^{i}$ & $39^{i}$ & 82 \\
\hline 17 & $\mathrm{Pd}(\mathrm{Piv})_{2}$ & Slow addn & ST & 5 & 2.18 & 94.25 & 0.88 & 96.9 & 2.2 & 5.3 & - & - & - \\
\hline 18 & $\mathrm{Pd}(\mathrm{Piv})_{2}$ & Initial & NB & 5 & 3.45 & 71.24 & 0.37 & 94.9 & 1.2 & 3.1 & $91^{i}$ & $91^{i}$ & 47 \\
\hline 19 & $\mathrm{Pd}(\mathrm{Piv})_{2}$ & Initial & NB & 10 & 2.15 & 70.97 & 0.29 & 96.7 & 1.2 & 3.3 & 124 & 129 & 34 \\
\hline 20 & $\mathrm{Pd}(\mathrm{Piv})_{2}$ & Slow addn & NB & 5 & 3.4 & 71.96 & 0.31 & 95.1 & 1.2 & 7.5 & - & - & - \\
\hline 21 & $\mathrm{Pd}(\mathrm{CO})(\mathrm{Ac})$ & Initial & - & 0 & 10.67 & - & 1.22 & - & - & 1.8 & 4 & 8 & - \\
\hline 22 & $\mathrm{Pd}(\mathrm{CO})(\mathrm{Ac})$ & Initial & HX & 5 & 9.6 & 45.32 & 0.6 & 81.6 & 1.4 & 2.0 & 6 & 6 & 453 \\
\hline 23 & $\mathrm{Pd}(\mathrm{CO})(\mathrm{Ac})$ & Initial & HX & 10 & 7.42 & 56.11 & 0.87 & 87.1 & 1.5 & 2.6 & 5 & 6 & 612 \\
\hline 24 & $\operatorname{Pd}(\mathrm{CO})(\mathrm{Ac})$ & Slow addn & HX & 5 & 5.77 & 49.37 & 1.28 & 87.5 & 1.5 & 4.7 & - & - & - \\
\hline 25 & $\mathrm{Pd}(\mathrm{CO})(\mathrm{Ac})$ & Initial & ST & 5 & 6.68 & 60.39 & 1.02 & 88.7 & 2.1 & 2.2 & 7 & 7 & 518 \\
\hline 26 & $\mathrm{Pd}(\mathrm{CO})(\mathrm{Ac})$ & Initial & ST & 10 & 5.25 & 64.04 & 0.8 & 91.4 & 2.1 & 2.1 & 11 & 15 & 296 \\
\hline 27 & $\mathrm{Pd}(\mathrm{CO})(\mathrm{Ac})$ & Slow addn & ST & 5 & 2.62 & 66.59 & 0.91 & 95.0 & 2.1 & 4.2 & - & - & - \\
\hline 28 & $\operatorname{Pd}(\mathrm{CO})(\mathrm{Ac})$ & Initial & NB & 5 & 4.65 & 45.89 & 1.47 & 88.2 & 1.5 & 3.4 & 7 & 6 & 424 \\
\hline 29 & $\mathrm{Pd}(\mathrm{CO})(\mathrm{Ac})$ & Initial & NB & 10 & 3.67 & 56.90 & 0.8 & 92.7 & 1.3 & 2.8 & 20 & 51 & 96 \\
\hline 30 & $\operatorname{Pd}(\mathrm{CO})(\mathrm{Ac})$ & Slow addn & NB & 5 & 1.7 & 75.67 & 0.52 & 97.2 & 1.2 & 2.9 & - & - & - \\
\hline 31 & $\mathrm{Pd}(\mathrm{CO})(\mathrm{Piv})$ & Initial & - & 0 & 14.9 & - & 1.81 & - & - & 1.6 & 4 & 8 & - \\
\hline 32 & $\mathrm{Pd}(\mathrm{CO})(\mathrm{Piv})$ & Initial & HX & 5 & 12.2 & 34.7 & 2.05 & 70.9 & 1.4 & 1.7 & 21 & 20 & 99 \\
\hline 33 & $\mathrm{Pd}(\mathrm{CO})(\mathrm{Piv})$ & Initial & HX & 10 & 8.75 & 47.27 & 1.23 & 82.5 & 1.3 & 1.5 & $14^{i}$ & $14^{i}$ & 203 \\
\hline 34 & $\mathrm{Pd}(\mathrm{CO})(\mathrm{Piv})$ & Slow addn & HX & 5 & 5.11 & 28.98 & 1.21 & 82.1 & 1.3 & 2.4 & - & - & - \\
\hline 35 & $\mathrm{Pd}(\mathrm{CO})(\mathrm{Piv})$ & Initial & ST & 5 & 7.5 & 50.97 & 1.36 & 85.2 & 2.1 & 2.1 & $23^{i}$ & $19^{i}$ & 146 \\
\hline 36 & $\mathrm{Pd}(\mathrm{CO})(\mathrm{Piv})$ & Initial & ST & 10 & 4.77 & 57.46 & 1.16 & 90.7 & 2.1 & 2.5 & $18^{i}$ & $19^{i}$ & 181 \\
\hline 37 & $\mathrm{Pd}(\mathrm{CO})(\mathrm{Piv})$ & Slow addn & ST & 5 & 3.44 & 29.01 & 1.72 & 84.9 & 1.9 & 2.4 & - & - & - \\
\hline 38 & $\mathrm{Pd}(\mathrm{CO})$ (Piv) & Initial & NB & 5 & 5.29 & 63.36 & 1.39 & 90.5 & 1.3 & 2.2 & 9 & 9 & 422 \\
\hline 39 & $\mathrm{Pd}(\mathrm{CO})(\mathrm{Piv})$ & Initial & NB & 10 & 2.94 & 58.90 & 0.53 & 94.4 & 1.2 & 2.1 & 37 & 36 & 97 \\
\hline 40 & $\mathrm{Pd}(\mathrm{CO})(\mathrm{Piv})$ & Slow addn & NB & 5 & 1.56 & 80.44 & 1.02 & 96.9 & 1.5 & 5.2 & - & - & - \\
\hline
\end{tabular}

${ }^{a}$ Solvent, toluene, $10 \mathrm{ml}, 1 \mathrm{~mol} \% \mathrm{Pd}$ (based on EDA), $30{ }^{\circ} \mathrm{C}$. The reactions were allowed to proceed until full consumption of EDA. ${ }^{b}$ Based on EDA and determined by GC. ${ }^{c}$ Initial: catalyst added to the reaction mixture at initial time. Slow addn: EDA added over $3 \mathrm{~h}$ time from a syringe pump. ${ }^{d} \mathrm{HX}$, 1-hexene; ST, styrene; NB, norbornene. ${ }^{e} 100 \mathrm{x}$ Yield cyclopropane/(yield cyclopropane + DEF + DEM + CI). ${ }^{f}$ Time for half consumption of EDA. ${ }^{g}$ Time for achieving $50 \%$ of the final product yield (cyclopropanes + DEF + DEM). ${ }^{h}$ GC signal for DEM could not be integrated. ${ }^{i}$ Calculated from $1{ }^{\text {st }}$ order rate constant.

terms of selectivity, however, the above-mentioned trend holds both at five and ten-fold olefin excess, as the amount of byproducts (DEF, DEM and CI) decrease on going from HX to ST to NB. In the third set of experiments, slow addition of EDA is intended to maintain near-zero concentration of this reagent during the reaction in order to minimize the formation of the carbene dimerization products, DEF and DEM. This effect is indeed achieved, and there is some increase of the cyclopropanation selectivity, especially for the less reactive olefin HX, but carbene dimerization is not fully suppressed. However, in terms of absolute cyclopropane yields, slow addition of EDA leads to irregular results, and albeit in some particular cases the cyclopropanation become nearly quantitative, in general this procedure means is no practical advantage. This is not entirely unexpected, since
DEF and DEM constitute just a small fraction of the reaction products and therefore their suppression would lead only to slight improvements in the cyclopropane yields.

In order to gain a better understanding on the origin of the selectivity of these cyclopropanation reactions, we carried out catalytic EDA decomposition experiments, under the same experimental conditions used in the cyclopropanation reactions (Entries $1,11,21$ and 31, Table 2). The behavior of the four catalysts is also similar in these experiments, producing low combined yields (10-15\%, full EDA consumption) of DEF and DEM, and minor amounts of CI, but no other significant products could be detected by GC. This indicates that small amounts of DEM and DEF are formed in cyclopropanation reactions because of an intrinsically low capability of intermediate palladium carbenoid species to 
perform carbene transfer to EDA or to the solvent. Noteworthy, the DEF/DEM ratio in the EDA decomposition reactions is close to 1.5 , lower than in most cyclopropanation reactions.

The course of the EDA decomposition and cyclopropanation reactions was systematically monitored by gas chromatography, except for slow EDA addition experiments. Rate laws determined for catalytic diazoalkane decomposition or cyclopropanation reactions, using rhodium ${ }^{11 b, 22}$ or copper ${ }^{23}$ catalysts have revealed first order dependencies on the diazoalkane. In our case, first order kinetics EDA consumption was occasionally observed, particularly for the slower reactions, but in general there are significant deviations from this simple rate law. For example, Fig. 2 displays first order plots for EDA decomposition and cyclopropanation reactions (olefin:EDA $=10: 1$ ) catalyzed by $\operatorname{Pd}(\mathrm{Piv})_{2}$ and $\mathrm{Pd}(\mathrm{CO})(\mathrm{Piv})$.
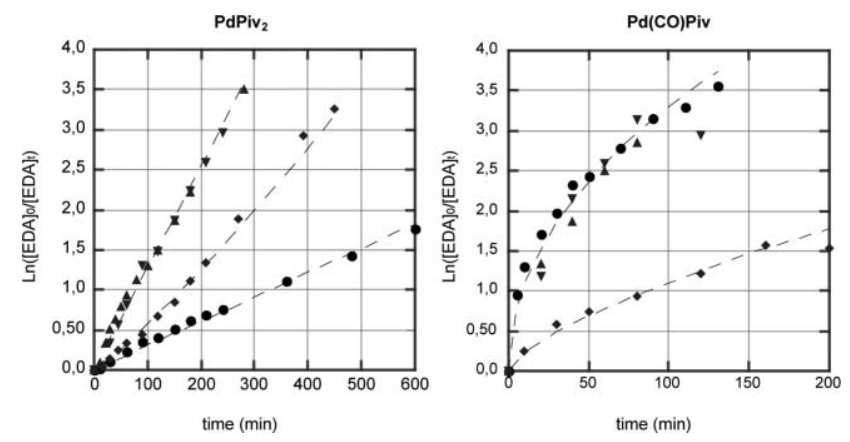

Fig. 2 First order plots for olefin cyclopropanation $(\boldsymbol{\Lambda}, \mathrm{HX} ; \boldsymbol{\nabla}, \mathrm{ST} ; \boldsymbol{\diamond}$ NB; olefin:EDA = 10:1) and EDA decomposition in the absence of added olefin $(\bullet)$ catalyzed by $\mathrm{Pd}(\mathrm{Piv})_{2}$ (right) and $\mathrm{Pd}(\mathrm{CO}) \mathrm{Piv}$ (left).

Although those for $\mathrm{Pd}(\mathrm{Piv})_{2}$ are linear or nearly linear, the $\mathrm{Pd}(\mathrm{CO})(\mathrm{Piv})$ plots display convex curves due to progressive decrease of the reaction rate. In order to provide a simple indication of the reaction rates, Table 2 lists the time required for the consumption of half the initial amount of EDA $\left(t_{50}\right)$, and that required to reach $50 \%$ of the final overall product yield $\left(t_{50}^{\prime}\right)$. In those experiments displaying well-behaved reaction kinetics, $t_{50}$ was evaluated from the apparent first order EDA consumption rate constants. As can be seen the two magnitudes are always close, indicating that the products are formed uniformly as EDA is consumed. Taking advantage of this observation, we have calculated the cyclopropanation TOF (turnover frequency numbers) at a half-conversion time on the basis of the half live reaction times (averaged $t_{50}$ and $t_{50}^{\prime}$ ), and the cyclopropanation yield. These are significantly larger for the acetate-based catalysts $\operatorname{Pd}(\mathrm{Ac})_{2}$ and $\mathrm{Pd}(\mathrm{CO})(\mathrm{Ac})$ than for the pivalate derivatives. The influence of catalyst structure (Pd(II) carboxylate or Pd(I) carbonyl carboxylate) is less marked, but $\mathrm{Pd}(\mathrm{CO})(\mathrm{Piv})$ is somewhat more active than $\mathrm{Pd}(\mathrm{Piv})_{2}$. Thus, cyclopropanation activities decrease in the order $\mathrm{Pd}(\mathrm{CO})(\mathrm{Ac}) \approx \mathrm{Pd}(\mathrm{Ac})_{2}>>\mathrm{Pd}(\mathrm{CO})(\mathrm{Piv})>$ $\operatorname{Pd}(\operatorname{Piv})_{2}$.

Interestingly, EDA decomposition rates in the absence of added olefin display a different trend. In the case of either of the two $\mathrm{Pd}(\mathrm{I})$ carbonyl carboxylates, they are similar to the HX and ST cyclopropanation reactions, but they are significantly slower for both Pd(II) carboxylates. This can be clearly appreciated in Fig. 2.

In cyclopropanation reactions, EDA consumption rates are similar or identical for ST and HX, no matter the catalyst used,
Table 3 Cyclopropanation competition experiments ${ }^{a}$

\begin{tabular}{|c|c|c|c|c|c|c|}
\hline \multirow[b]{2}{*}{ Entry } & \multirow[b]{2}{*}{ Catalyst } & \multicolumn{2}{|c|}{ trans/cis } & \multicolumn{3}{|c|}{ Selectivity } \\
\hline & & HX & ST & HX $(\%)$ & ST $(\%)$ & ST/HX \\
\hline 1 & $\operatorname{Pd}(\mathrm{Ac})_{2}$ & 1.5 & 2.1 & 29 & 67 & 2.3 \\
\hline 2 & $\mathrm{Pd}(\mathrm{Piv})_{2}$ & 1.5 & 2.1 & 31 & 63 & 2.1 \\
\hline 3 & $\mathrm{Pd}(\mathrm{CO})(\mathrm{Ac})$ & 1.4 & 2.1 & 30 & 66 & 2.2 \\
\hline 4 & $\mathrm{Pd}(\mathrm{CO})(\mathrm{Piv})$ & 1.4 & 2.3 & 28 & 68 & 2.4 \\
\hline
\end{tabular}

${ }^{a}$ Reaction conditions: toluene $1 \mathrm{~mol} \% \mathrm{Pd}, 30^{\circ} \mathrm{C}$. EDA:HX:ST $=1: 5: 5$. EDA slowly added $(3 \mathrm{~h})$ from a syringe pump.

but slower with NB, particularly when the concentration of this olefin is highest. The apparent contrast with the above mentioned olefin reactivity order $\mathrm{HX}<\mathrm{ST}<\mathrm{NB}$ indicates that the overall reaction rate is not controlled by the olefin reactivity but by the reaction EDA with the catalyst. Thus, in order to check whether the relative olefin reactivity order holds for the different palladium carboxylate and carbonyl-carboxylate complexes, we carried out a set of competition experiments using equimolar mixtures of HX and ST, under slow addition conditions. These reactions led to cyclopropane mixtures with the same cis/trans ratio observed in the previous experiments. As can be seen in Table 3, ST and HX are cyclopropanated in $c a .2 .2$ ratio, independently of the catalyst. This is close to the $1.8 \mathrm{ST} / \mathrm{HX}$ cyclopropanation ratio reported by Noels et al., and thus it is reasonable to assume that the reactivity of NB relative to HX is higher, similar to that given by this author, i.e., 6.4 .

Scheme 3 shows a simplified diagram summarizing current ideas on the mechanism of metal-catalyzed diazoalkane carbenetransfer reactions., ${ }^{3116,12-14}$ Reversible coordination of the diazoalkane competes with other potentially binding substrates, and is followed by slow, rate limiting nitrogen elimination, which leads to the formation of the carbenoid species. The carbene transfer step is fast and irreversible, and therefore has no influence on the diazoalkane consumption rate. These features are in agreement with the roughly equal $t_{50}$ values observed for HX and ST cyclopropanation on doubling the olefin concentration, and with the inhibitory effect of a strongly binding olefin such as NB, which probably competes with the diazoalkane for the catalytic site (compare, for instance, entries 28-29 and 38-39 in Table 2). A similar inhibitory effect exerted by DEF and DEM, could help to explain the deviations from first order kinetics observed in many cyclopropanation reactions, as well as in EDA decomposition in the absence of added olefin. The fact that such effects are less apparent for $\mathrm{PdPiv}_{2}$ than for other catalysts suggests that steric effects could hinder olefin coordination in this particular case.

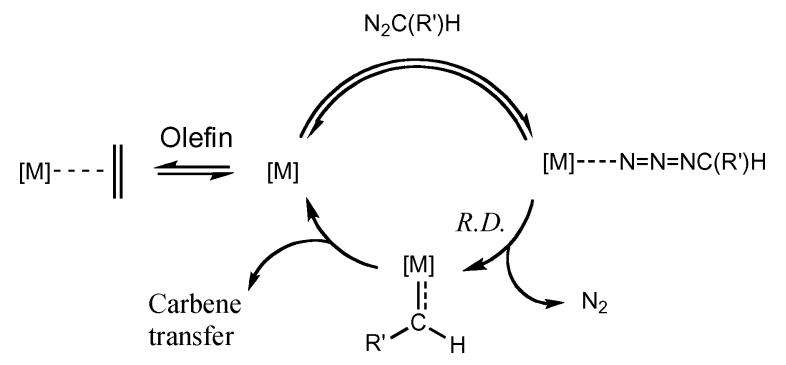

Scheme 3 
The important differences between acetate and pivalate catalysts in the overall reaction rates can be taken as an indication of the permanence of the carboxylate group in the active species, modulating the catalyst activity. As described in the Introduction, the nature of the active species involved in this kind of reactions is still a subject of much discussion. In many cases, for example for rhodium carboxylates, it is assumed that the structure of the catalyst precursor is essentially maintained in the process, but palladium acetate is thought to undergo an activation process that drastically modifies the oligomeric structure of this compound. Full reduction to $\operatorname{Pd}(0)$ species would lead to essentially the same catalytic species, with independency of the type of carboxylate group present in the catalyst precursor. On the other hand, the initial oxidation state of the catalyst appears to exert only a minor influence on their performance. Therefore, in order to explain our data, partial reduction to $\mathrm{Pd}(\mathrm{II})$ carboxylates to $\mathrm{Pd}(\mathrm{I})$ species becomes an attractive proposal. This would lead to similar, though not necessarily identical, active species, with comparable activities from either carboxylate or carbonyl carboxylate precursors. The tetranuclear diphenylcarbene complex $\left[\mathrm{Pd}\left(\mu-\mathrm{MeCO}_{2}\right)(\mu-\right.$ $\left.\left.\mathrm{CPh}_{2}\right)\right]_{4}$ can be envisaged as model for such $\mathrm{Pd}(\mathrm{I})$ intermediates. Notwithstanding this, much caution is advisable on this regard, as the proposal of a single kind of catalytic species might be a simplification of a more complex mechanistic situation, involving more than a single catalytic species.

Some support for a polynuclear active species comes from the relatively high DEF/DEM ratios observed in cyclopropanation reactions, which increase to values al large as 7 under slow EDA addition conditions. It is generally assumed that these carbene-coupling products arise from a nucleophilic attack of EDA on the coordinated carbene, but Graban and Lemke have observed that some ruthenium complexes strongly favor DEF over DEM production at high catalyst concentration, attributing this phenomenon to a bimetallic carbene coupling process. ${ }^{24}$ The stereoselectivity of this bimetallic process is favored by the sterically less demanding anti arrangement of the $\mathrm{C}\left(\mathrm{CO}_{2} \mathrm{Et}\right) \mathrm{H}$ units. We carried out an independent styrene cyclopropanation experiment $\left(\mathrm{Pd}(\mathrm{Ac})_{2}\right.$, slow addition conditions) increasing 10 times the catalyst concentration, but no significant increase of the DEF/DEM ratio was observed $(\approx 4)$, suggesting that selective DEF formation occurs intramolecularly. A bimetallic, intramolecular carbene coupling process suggests the intermediacy of a polynuclear palladium intermediate. $^{25}$

After the rate-determining step, a number of carbene transfer reactions take place, including transfer to olefin (cyclopropanation), carbene coupling to produce DEM and DEF, transfer to the solvent, and, presumably, carbene oligomerization or polymerization. Although these have no influence on the EDA consumption rate, final cyclopropanation selectivities depend upon the relative rate constants of such processes, which are expected to be sensitive to the structure of the catalyst and to the nature of its interaction with the substrate. For cyclopropanation, the sequence of relative olefin reactivities determined by Noels et al. correlates well with their capability to bind to the metal. Accordingly, a carbene transfer mechanism involving alkene coordination and palladacyclobutane formation has been proposed, ${ }^{11 \mathrm{~b}}$ at variance with direct attack of the olefin on the coordination carbene, usually accepted for other elements different of palladium. ${ }^{2}$ The former mechanism is supported by theoretical investigations of the palladium-catalyzed reaction. ${ }^{14}$ Carboxylate ligands can facilitate olefin coordination by switching from bridging to terminal coordination mode. However, since this capability is expected to depend both on the properties of the carboxylate group as well as the type of olefin, it is somewhat surprising that the $\mathrm{ST} / \mathrm{HX}$ relative reactivity ratio is virtually identical for the four catalysts. Furthermore, different coordination environments generated by acetate or pivalate groups should influence the trans/cis ratio as well, but these are also very similar. Of course, it is possible that the carboxylate $\mathrm{R}$ groups are simply too far removed to exert any important influence on the catalyst. For example, such steric effects are negligible for $\mathrm{Rh}(\mathrm{II})$ carboxylates unless extremely bulky $2,2^{\prime}$-diarylbenzoate groups are used as ligands. ${ }^{26}$ For other catalysts, however, ligand size allows very efficient control over the trans/cis cyclopropanation ratio. ${ }^{27}$ An alternative explanation to the apparent lack of selectivity control of the palladium-catalyzed cyclopropanations could be a mechanism involving the release of free ethoxycarbonylcarbene from the metal carbenoid. In this case, the relative rates of the subsequent reaction of the carbene with olefins, solvent or EDA would be the same independently of the catalyst, and the olefin reactivity order would be related to their reactivity towards the electrophilic carbene rather than to their affinity metal center. Carbene dissociation is an unusual kind of mechanism, but it has been proposed to occur in alkane functionalization with diethyldiazomalonate catalyzed by $\mathrm{Rh}$ (II) derivatives of strong carboxylic acids. ${ }^{28}$ In order to have an indication of the involvement of free carbenes in our reaction, we carried out a test consisting in the measurement of the relative rates of carbene insertion in benzene and cyclohexane (Scheme 4). For photochemically generated ethoxycarbonylcarbene, the benzene/cyclohexane insertion ratio is 0.83 , whilst very different values, higher than 6 , have been measured for $\mathrm{Rh}^{27,29}$ and $\mathrm{Ag}^{30}$ catalyzed reactions, for which the carbene delivery is thought to occur in the metal coordination sphere. In contrast, palladium carboxylates and carbonyl carboxylate complexes produce low yields $(\mathrm{ca} .2 \%)$ of the benzene and cyclohexane functionalization products in 1.5-1.8 ratio. Although twice as much as reported for the free carbene, these values point more to the latter rather than to a metal carbenoid intermediate. In addition, the similarity of the values also implies that the metal fragment exerts little influence on the carbene insertion ratios. Thus, we consider that the intermediacy of free ethoxycarbonylcarbene, released from the palladium carbenoid, is a plausible mechanistic possibility for this type of catalysts, although much caution should be used with this conclusion (especially in view of the low yields of the alkane insertion reactions). The full elucidation of this point will require further mechanistic investigation.

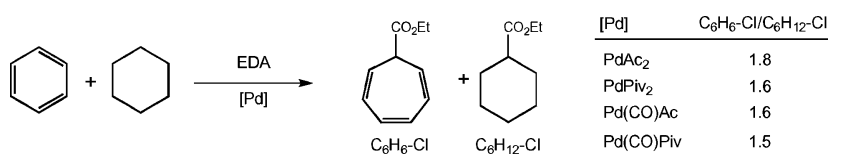

Scheme 4

\section{Conclusions}

Palladium carbonyl carboxylates $\mathrm{Pd}(\mathrm{CO})(\mathrm{Ac})$ and $\mathrm{Pd}(\mathrm{CO})(\mathrm{Piv})$ catalyze the cyclopropanation of olefins (HX, ST and NB) with 
EDA. The performance of these catalysts is similar to that of the corresponding palladium(II) carboxylates $\mathrm{Pd}(\mathrm{Ac})_{2}$ and $\mathrm{Pd}(\mathrm{Piv})_{2}$, affording mixtures of the cis and trans cyclopropanes (50-90\%), together with minor amounts of diethyl fumarate and maleate (DEF and DEM, 2-10\%) and traces of the products resulting from the insertion ethoxycarbonylcarbene into the solvent (CI, $<2 \%$ ).

The use of $\operatorname{Pd}(\mathrm{I})$ or $\mathrm{Pd}(\mathrm{II})$ catalysts mean no important differences in terms of absolute cyclopropanation yields. However, reaction rates are significantly higher for the acetate based catalysts $\left(\mathrm{Pd}(\mathrm{Ac})_{2}, \mathrm{Pd}(\mathrm{CO})(\mathrm{Ac})\right)$ than for the more encumbered pivalates $\left(\mathrm{Pd}(\mathrm{Piv})_{2}, \mathrm{Pd}(\mathrm{CO})(\mathrm{Piv})\right)$. This fact, coupled with other observations, suggests that the main active species could be partially reduced $\mathrm{Pd}$ complexes which retain carboxylate ligands in their structure, possibly polynuclear $\mathrm{Pd}(\mathrm{I})$ carbenoids, structurally related to the diphenylcarbene cluster $\left[\mathrm{Pd}(\mu-\mathrm{CO})\left(\mu-\mathrm{CPh}_{2}\right)\right]_{4}$.

Rather surprisingly, the size of the carboxylate ligand has no influence on the selectivity control of the cyclopropanation reaction. In addition, competition experiments show that the relative reactivities of $\mathrm{ST}$ and $\mathrm{HX}$ are the same regardless the carboxylate present in the catalyst. The lack of influence of the carboxylate ligand size suggests that carbene transfer involves free ethoxycarbonylcarbene $(: \mathrm{C}(\mathrm{OEt}) \mathrm{H})$, which acts as the actual cyclopropanating agent. EDA decomposition experiments carried out in 1:1 benzene/cyclohexane mixtures showed very low level of discrimination in the formation of the two carbene insertion products, giving some additional support to the latter hypothesis.

\section{Experimental}

Most operations were carried out under oxygen-free nitrogen or argon atmosphere by conventional Schlenk techniques or in a nitrogen-filled glove-box. Toluene, benzene and cyclohexane were freshly distilled from sodium prior to use. 1-Hexene, styrene and norbornene were purchased from Aldrich and used as received. Palladium acetate,${ }^{31}$ pivalate,${ }^{31}$ carbonylacetate ${ }^{18 a}$ and carbonylpivalate ${ }^{18 \mathrm{~b}}$ were prepared according to literature methods. NMR spectra were recorded on Bruker DRX 300 or DPX 500. Quantitative GC analysis were performed in a Agilent 68090 Series chromatograph with TCD detector, using mesitylene as an internal standard, and qualitative product identification in a ThermoQuest Trace GC 2000 Series with Automass Multi mass spectrometer detector. Both instruments were equipped with Tecnokroma TRB1 (polymethylsiloxane) $30 \mathrm{~m}$ capillary columns, using the same oven temperature program.

\section{Catalytic experiments}

a) "Initial" conditions. A mixture containing $7.5 \mathrm{ml}$ of toluene, $0.570 \mathrm{~g}$ of EDA ( $5 \mathrm{mmol}$ ), 25 or $50 \mathrm{mmol}$ of olefin (HX, ST or NB, 5 or 10 -fold excess relative to EDA) and $0.25 \mathrm{ml}$ of mesitylene (as internal standard) was placed in a glass ampoule with Teflon valve and magnetic stirrer. Prior to the catalyst addition, the mixture was analyzed by GC. Then the ampoule was placed in a $30^{\circ} \mathrm{C}$ oil bath and a solution containing $50 \mu$ Equiv of the catalyst $(1 \mathrm{~mol} \mathrm{Pd} \%$, based on EDA) in $2.5 \mathrm{ml}$ of toluene was added. The mixture was stirred at this temperature, taking samples at periodic intervals, which were filtered in a short silica pad and analyzed by GC, until full consumption of EDA. EDA decomposition reactions were done similarly, but replacing the volume of the olefin by solvent (toluene, $10 \mathrm{ml}$ ). For selected examples, the identity of the final products was confirmed by GC-MS, and ${ }^{1} \mathrm{H}$ NMR, diluting a sample of the final mixture with $\mathrm{CDCl}_{3}$.

b) Slow addition conditions. A mixture of olefin $(12.5 \mathrm{mmol})$, toluene $(5 \mathrm{ml})$, mesitylene $(0.25 \mathrm{ml})$ and $25 \mu$ Equiv $(1 \mathrm{~mol} \mathrm{Pd} \%$ based on EDA) was placed in a Schlenk tube capped with a septum and furnished with a magnetic stirrer. A sample was taken for GC analysis. A solution of EDA $(0.285 \mathrm{~g}, 2.5 \mathrm{mmol})$ in $5 \mathrm{ml}$ of toluene was added over $3 \mathrm{~h}$ via cannula from a syringe pump (injection rate $1.67 \mathrm{ml} / \mathrm{h}$ ) to the mixture stirred at $30^{\circ} \mathrm{C}$. The mixture was stirred for 10 additional minutes, and analyzed by GC as described for the initial method. A special run was done for NMR characterization of the NB cyclopropane derivatives, using $\mathrm{Pd}(\mathrm{CO}) \mathrm{Piv}$ as a catalyst without mesitylene standard. The reaction mixture was filtered through a pad of silica gel and taken to dryness to remove solvent and norbornene excess. The spectra showed a nearly pure mixture of the cis and trans cyclopropanes.

c) Competition cyclopropanation experiments. These experiments were carried out at $30{ }^{\circ} \mathrm{C}$ under slow addition conditions using $2.60 \mathrm{~g}(25 \mathrm{mmol})$ of styrene, $2.10 \mathrm{~g}(25 \mathrm{mmol})$ of 1 -hexene, $5 \mathrm{ml}$ of toluene and $50 \mu$ Equiv of catalyst ( $1 \mathrm{~mol} \mathrm{Pd} \%$ based on EDA). A solution of EDA $(0.57 \mathrm{~g}, 5 \mathrm{mmol})$ in toluene $(5 \mathrm{ml})$ was added from a syringe pump over $3 \mathrm{~h}$. The mixture was stirred for 30 additional minutes and analyzed by GC as described before.

d) High catalyst concentration experiments. A typical slow addition experiment for styrene cyclopropanation was carried out using $250 \mu$ Equiv of $\operatorname{Pd}(\mathrm{Ac})_{2}$ catalyst.

e) Competition carbene insertion experiments. These were done at $30{ }^{\circ} \mathrm{C}$ under slow addition conditions, using an equimolar mixture of benzene and cyclohexane (3:2.5 in volume) as solvent. $50 \mu$ Equiv of catalyst were dissolved in $5.5 \mathrm{ml}$ of the solvent mixture. A solution of EDA $(0.57 \mathrm{~g}, 5 \mathrm{mmol})$ in $5.5 \mathrm{ml}$ of the same benzene/cyclohexane mixture was added over $3.3 \mathrm{~h}$. The mixture was stirred for 30 additional minutes and analyzed by GC as described before. Carbene insertion products were identified by GC-MS.

\section{Computational details for the calculation of NMR chemical shifts}

Guess structures for the four possible cyclopropanation products of norbornene were computed with molecular mechanics using the Merck Molecular Force Field as implemented in the Spartan 02 package. ${ }^{32}$ A conformational search was applied in order to locate the most stable conformation of the ethoxycarbonyl group in each case. The resulting structures were then optimized at the HF level using 6-311+G(2d,p) basis functions in the program Gaussian $03 .{ }^{33}$ Chemical shifts were then computed with the GIAO method at the same level of theory.

\section{Acknowledgements}

Financial support by CSIC and the Russian Foundation for Basic Research (Project 2008RU0055/09-03-91284) is gratefully acknowledged. We also thank the Junta de Andalucía (Project P06-FQM-01704) for additional support. 


\section{Notes and references}

1 See for example: (a) F. D. Özdemirhan, M. Çelik, S. Atli and C. Tanyelia, Tetrahedron: Asym., 2006, 17, 287-291; (b) B. Schönecker and C. Lange, J. Organomet. Chem., 2006, 691, 2107-2124; (c) A. Kurek-Tyrlik, K. Michalak and J. Wicha, J. Org. Chem., 2005, 70, 8513-8521; (d) R. Faust, Angew. Chem., Int. Ed., 2001, 40, 2251-2253, and references therein.

2 (a) The Chemistry of the Cyclopropyl Group, ed. Z. Rappaport, Wiley, New York, 1995; (b) J. Salaün, Chem. Rev., 1989, 89, 1247-1270; (c) W. A. Donaldson, Tetrahedron, 2001, 41, 8589-8627.

3 (a) M. P. Doyle, Chem. Rev., 1986, 86, 919-939; (b) M. P. Doyle and D. C. Forbes, Chem. Rev., 1998, 98, 911-935; (c) A. F. Noels and A. Demonceau, in Applied Homogeneous Catalysis with Organometallic Compounds, A Comprehensive Handbook in Three Volumes, 2nd, Completely Revised and Enlarged Edition, ed. B. Cornils and W. A. Herrmann, Wiley, Weinheim, 2002; (d) Z. H. Zhang and J. B. Wang, Tetrahedron, 2008, 64, 6577-6605; (e) T. Ye and M. A. McKervey, Chem. Rev., 1994, 94, 1091-1160; (f) H. Lebel, J.-F. Marcoux, C. Molinaro and A. B. Charette, Chem. Rev., 2004, 104, 977-1050; $(g)$ A. Caballero, A. Prieto, M. M. Díaz-Requejo and P. J. Perez, Eur. J. Inorg. Chem., 2009, $1137-1144$

4 For Rh complexes catalyzed cyclopropanation see for example: $(a) \mathrm{V} . \mathrm{K}$. Aggarwal, J. Vicente and R. V. Bonnert, Org. Lett., 2001, 3, 2785-2788; (b) A. G. M. Barrett, D. C. Braddock, I. Lenoir and H. Tone, J. Org. Chem., 2001, 66, 8260-8263; (c) Y. Lou, M. Horikawa, R. A. Kloster, N. A. Hawryluk and E. J. Corey, J. Am. Chem. Soc., 2004, 126, 8916-8918; (d) F. Estevan, J. Lloret, M. Sanaú and M. A. Úbeda, Organometallics, 2006, 25, 4977-4984; (e) J. Lloret, F. Estevan, K. Bieger, C. Villanueva and M. A. Úbeda, Organometallics, 2007, 26, 4145-4151.

5 Cu catalysts: see for example: $(a)$ M. M. Díaz-Requejo, T. R. Belderraín, S. Trofimenko and P. J. Pérez, J. Am. Chem. Soc., 2001, 123, 3167-3168; (b) M. P. A. Lyle and P. D. Wilson, Org. Lett., 2004, 6, 855-857; (c) M. Itagaki, K. Masumoto and Y. Yamamoto, J. Org. Chem., 2005, 70, 3292-3295; (d) M. Itagaki and K. Suenobu, Org. Proc. Res. Develop., 2007, 11, 509-518 and references therein.

6 Co catalysts catalyzed cyclopropanation, see for example: (a) S. Fantuzzi, E. Gallo, E. Rose, N. Raoul, S. Issa, F. Ragaini and S. Cenini, Organometallics, 2008, 27, 6143-6151; (b) Y. Chen, J. V. Ruppel and X. P. Zhang, J. Am. Chem. Soc., 2007, 129, 12074-12075; (c) Y. Chen, K. B. Fields and X. P. Zhang, J. Am. Chem. Soc., 2004, 126, 14718-14719.

$7 \mathrm{Ru}$ complexes catalyzed cyclopropanation, see for example: (a) H. M. Lee, C. Bianchini, G. Jia and P. L. Barbaro, Organometallics, 1999, 18, 1961-1966; (b) N. E. Leadbeater, K. A. Scott and L. J. Scott, J. Org. Chem., 2000, 65, 3231-3232; (c) J.-L. Zhang and C.-M. Che, Org. Lett., 2002, 4, 1911-1914; (d) Y. Ferrand, P. Maux and G. Simonneaux, Org. Lett., 2004, 6, 3211-3214; (e) Y. Sevryugina, B. Weaver, J. Hansen, J. Thompson, H. M. L. Davies and M. A. Patrukhina, Organometallics, 2008, 27, 1750-1757.

8 (a) P. F. Teng, C. S. Tsang, H. L. Yeung, W. L. Wong, W. T. Wong and H. L. Kwong, J. Organomet. Chem., 2006, 691, 5664-5672; (b) M. D. Khanova, R. M. Sultanova, S. S. Zlotskii, V. A. Dokichev and Y. V. Tomilov, Russ. Chem. Bull., 2005, 54, 1003-1007; (c) M. L. Kantam, Y. Haritha, N. M. Reddy, B. M. Choudary and F. Figueras, Catal. Lett., 2002, 83, 187-190; (d) M. Dubs, H. Dieks, W. Gunther, M. Kotteritzsch, W. Poppitz and B. Schonecker, Tet. Lett., 2002, 43, 2499-2503; (e) K. J. Miller, J. H. Baag and M. M. Abu-Omar, Inorg. Chem., 1999, 38, 4510-4514; (f) S. E. Denmark, R. A. Stavenger, A. M. Faucher and J. P. Edwards, J. Org. Chem., 1997, 62, 3375-3389; (g) R. Navarro, E. P. Urriolabeitia, C. Cativela, M. D. Diez de Villegas, M. P. López and E. J. Alonso, J. Mol. Catal. A, 1996, 105, 111.

9 (a) M. P. Doyle and M. A. McKervey, Chem. Commun., 1997, 983; (b) J. Hansen and H. M. L. Davies, Coord. Chem. Rev., 2008, 252, 545-555.

10 (a) S. I. Kozhushkov, D. S. Yufit, R. Boese, D. Blaser, P. R. Schreiner and A. de Meijere, Eur. J. Org. Chem., 2005, 1409-1415; (b) E. V. Guseva, N. V. Volchkov, Y. V. Tomilov and O. M. Nefedov, Eur. J. Org. Chem., 2004, 3136-3144; (c) M. Dubs, H. Dieks, W. Gunther, M. Kotteritzsch, W. Poppitz and B. Schonecker, Tetrahedron Lett., 2002, 43, 2499-2503; (d) I. E. Markó, T. Kumamoto and T. Girad, Adv. Synth. Catal., 2002, 344, 1063-1067.

11 (a) M. W. Majchrzak, A. Kotelko and J. B. Lambert, SynthesisStuttgart, 1983, 469-470; (b) A. J. Ancieaux, A. Demonceau, A. F. Noels, A. Hubert, R. Warin and P. Teyssié, J. Org. Chem., 1981, 46, 873-876.
12 F. Bernardi, A. Bottoni and G. P. Miscione, Organometallics, 2001, 20, 2751-2758.

13 C. Rodríguez-García, A. Oliva, R. M. Ortuño and V. Branchadell, $J$. Am. Chem. Soc., 2001, 123, 6157.

14 B. F. Straub, J. Am. Chem. Soc., 2002, 124, 14195-14201.

15 (a) M. Bröring, C. D. Brandt and S. Stellwag, Chem. Commun., 2003, 2344-2345; (b) W. A. Herrmann, K. Öfele, S. K. Schneider, E. Herdtweck and S. D. Hoffmann, Angew. Chem., Int. Ed., 2006, 45, 3859-3862; (c) W. A. Herrmann, K. Öfele, C. Taubmann, E. Herdtweck and S. D. Hoffmann, J. Organomet. Chem., 2007, 692, 3846-3854; (d) D. F. Wass, T. W. Hey, J. Rodriguez-Castro, C. A. Russell, I. V. Shishkov, R. L. Wingad and M. Green, Organometallics, 2007, 26, 4702-4703.

16 T. A. Stromnova, I. N. Busygina, D. I. Kochubey and I. I. Moiseev, Mendeleev Commun., 1991, 1-2.

17 O. Illa, C. Rodríguez-García, C. Acosta-Silva, I. Favier, D. Picurelli, A. Oliva, M. Gómez, V. Branchadell and R. M. Ortuño, Organometallics, 2007, 26, 3306-3314.

18 (a) I. I. Moiseev, T. A. Stromnova, M. N. Vargaftik, G. Ya Mazo, L. G. Kuz'mina and T. Yu Struchkov, J. Chem. Soc., Chem. Commun., 1978, 27-28; (b) T. A. Stromnova, O. N. Shishilov, L. I. Boganova, N. A. Minaeva, A. V. Churakov, L. G. Kuz'mina and J. A. K. Howard, Russ. J. Inorg. Chem., 2005, 50, 179-186; (c) T. A. Stromnova, O. N. Shishilov, M. V. Dayeko, K. Yu Monhakov, A. V. Churakov, L. G. Kuz'mina and J. A. K. Howard, J. Organomet. Chem., 2006, 691, 3730-3736.

19 M. E. Morilla, M. N. Díaz-Requejo, T. R. Belderraín, M. C. Nicasio, S. Trofimenko and P. J. Pérez, Organometallics, 2004, 23, 293-295.

20 P. J. Pérez, M. Brookhart and J. L. Templeton, Organometallics, 1993, 12, 261-262.

21 (a) R. R. Sauers and P. E. Sonnet, Tetrahedron, 1964, 20, 1029-1035; (b) W. D. Nielsen, R. D. Larsen and P. W. Jennings, J. Am. Chem. Soc., $1988,110,8657-8569$

22 (a) M. C. Pirrung and A. T. Morehead Jr., J. Am. Chem. Soc., 1996, 118, 8162-8163; (b) M. C. Pirrung, H. Liu and A. T. Morehead Jr., J. Am. Chem. Soc., 2002, 124, 1014-1023.

23 (a) M. M. Díaz-Requejo, T. R. Belderrain, M. C. Nicasio, F. Prieto and P. J. Pérez, Organometallics, 1999, 18, 2601-2609; (b) R. L. Safiullin, V. A. Dokichev, L. R. Yakupova, R. M. Sultanova, S. L. Khursan, R. N. Zaripov and Yu. V. Tomilov, Kinet. Catal., 2008, 49, 43-51 and refs. therein.

24 E. Graban and F. R. Lemke, Organometallics, 2002, 21, 38233826.

25 There is some precedent for coupling of bridging carbene ligands: $(a) \mathrm{M}$. Akita, R. Hua, S. A. R. Knox, Y. Moro-Oka, S. Nakanishi and M. J. Yates, J. Organomet. Chem., 1998, 569, 71-83; (b) A. Schafer and W. A. Herrmann, J. Organomet. Chem., 1985, 297, 229-243.

26 H. J. Callot and F. Metz, Tetrahedron, 1985, 41, 4495-4501.

27 M. M. Díaz-Requejo, A. Caballero, T. R. Belderraín, M. C. Nicasio, S. Trofimenko and P. J. Pérez, J. Am. Chem. Soc., 2002, 124, 978-983.

28 A. Demonceau, A. F. Noels and J.-L. Costa, J. Mol. Catal. A, 1990, 58, 21-26.

29 A. J. Anciaux, A. Demonceau, A. F. Noels, A. J. Hubert, R. Warin and P. Teyssie, J. Org. Chem., 1981, 46, 873-876.

30 J. Urbano, T. R. Belderraín, M. C. Nicasio, S. Trofimenko, M. M. Díaz-Requejo and P. J. Pérez, Organometallics, 2005, 24, 1528-1532.

31 T. A. Stephenson, S. M. Morehouse, A. R. Powell, J. P. Heffer and G. Wilkinson, J. Chem. Soc., 1965, 3632-3640.

32 SPARTAN 02, Wavefunction, Inc., Irvine, CA.

33 M. J. Frisch, G. W. Trucks, H. B. Schlegel, G. E. Scuseria, M. A. Robb, J. R. Cheeseman, J. A. Montgomery, Jr., T. Vreven, K. N. Kudin, J. C. Burant, J. M. Millam, S. S. Iyengar, J. Tomasi, V. Barone, B. Mennucci, M. Cossi, G. Scalmani, N. Rega, G. A. Petersson, H. Nakatsuji, M. Hada, M. Ehara, K. Toyota, R. Fukuda, J. Hasegawa, M. Ishida, T. Nakajima, Y. Honda, O. Kitao, H. Nakai, M. Klene, X. Li, J. E. Knox, H. P. Hratchian, J. B. Cross, V. Bakken, C. Adamo, J. Jaramillo, R. Gomperts, R. E. Stratmann, O. Yazyev, A. J. Austin, R. Cammi, C. Pomelli, J. Ochterski, P. Y. Ayala, K. Morokuma, G. A. Voth, P. Salvador, J. J. Dannenberg, V. G. Zakrzewski, S. Dapprich, A. D. Daniels, M. C. Strain, O. Farkas, D. K. Malick, A. D. Rabuck, K. Raghavachari, J. B. Foresman, J. V. Ortiz, Q. Cui, A. G. Baboul, S. Clifford, J. Cioslowski, B. B. Stefanov, G. Liu, A. Liashenko, P. Piskorz, I. Komaromi, R. L. Martin, D. J. Fox, T. Keith, M. A. Al-Laham, C. Y. Peng, A. Nanayakkara, M. Challacombe, P. M. W. Gill, B. G. Johnson, W. Chen, M. W. Wong, C. Gonzalez and J. A. Pople, GAUSSIAN 03 (Revision C.02), Gaussian, Inc., Wallingford, CT, 2004. 